\title{
Wegener's granulomatosis: isolated involvement of the trachea and larynx
}

\author{
DAVID HELLMANN. 'TIMOTHY LAING ? MICHELLE PETRI. ' \\ DON JACOBS, ${ }^{3}$ ROGER CRUMLEY. AND MICHAEL STULBARG
}

From the 'Department of Medicine, Johns Hopkins University; and the Department of 'Medicin's

${ }^{3}$ Pathology, and ${ }^{4}$ Otolaryngology, University of California, San Francisco

SUMmaRY A 26 year old man with subacute hoarseness and stridor was shown to have Wegener's granulomatosis isolated to the trachea and larynx. Although isolated larynge Wegener's is unusual, a review of the literature suggests that early treatment with cyclophos phamide is warranted.

Key words: vasculitis, cyclophosphamide, stridor.

Wegener's granulomatosis typically presents as sinusitis, pulmonary infiltrates, and glomerulonephritis. ${ }^{1-3}$ Occasionally, Wegener's granulomatosis appears, at least initially, to involve only one organ or one region, most commonly the lung. ${ }^{2}+$ Wegener's granulomatosis isolated to the tracheolarynx is rare and especially difficult to recognise since biopsies of this region rarely demonstrate vasculitis. ${ }^{5-11}$ In an effort to promote early diagnosis of this now treatable disorder we report a case of isolated tracheolaryngeal Wegener's granulomatosis and review the pertinent literature.

\section{Case report}

A previously healthy 26 year old man was referred in July 1985 for evaluation of hoarseness, stridor, and dyspnoea. He had lost $3.5 \mathrm{~kg}$ but denied other symptoms. A detailed general physical examination was normal. Indirect laryngoscopy showed the subglottic larynx to be greatly narrowed circumferentially by boggy, erythematous folds of redundant tissue. The vocal cords were mobile.

The blood counts, chemistries, and urine analysis were normal. Skin tests for tuberculosis and coccidioidomycosis were negative. Chest and sinus $x$ rays were normal. A computed axial tomographic

Accepted for publication 17 March 1987.

Correspondence to Dr David Hellmann. 1012 Blalock. The Johns Hopkins Hospital. Baltimore. MD 21215. USA.

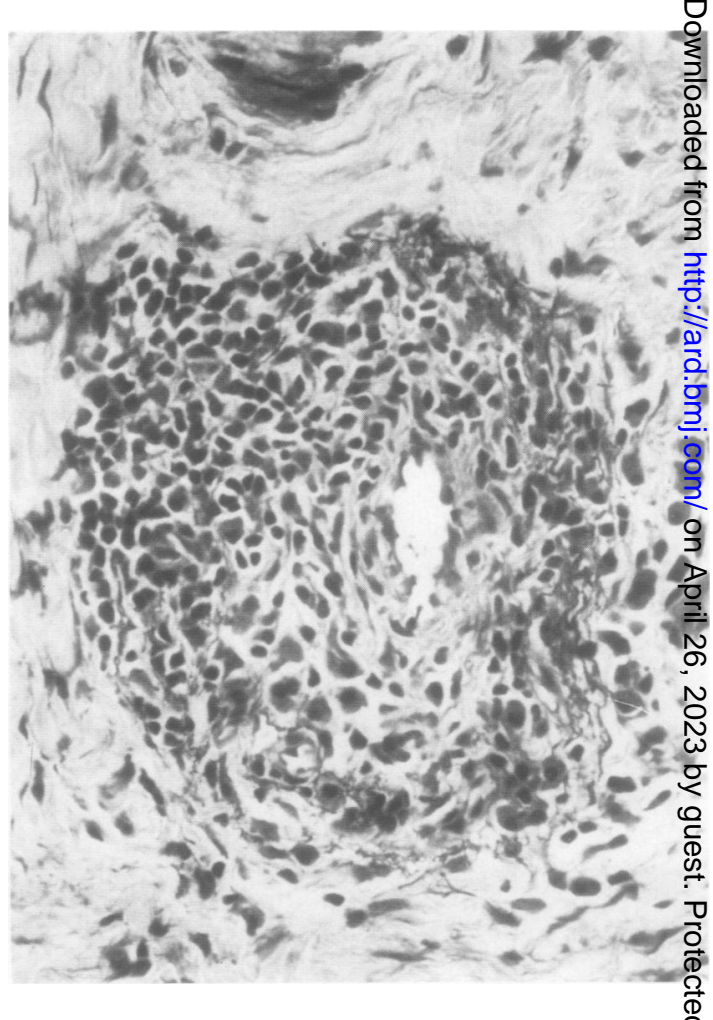

Fig. I Laryngeal biopsy specimen showing small ves:el vasculitis. 


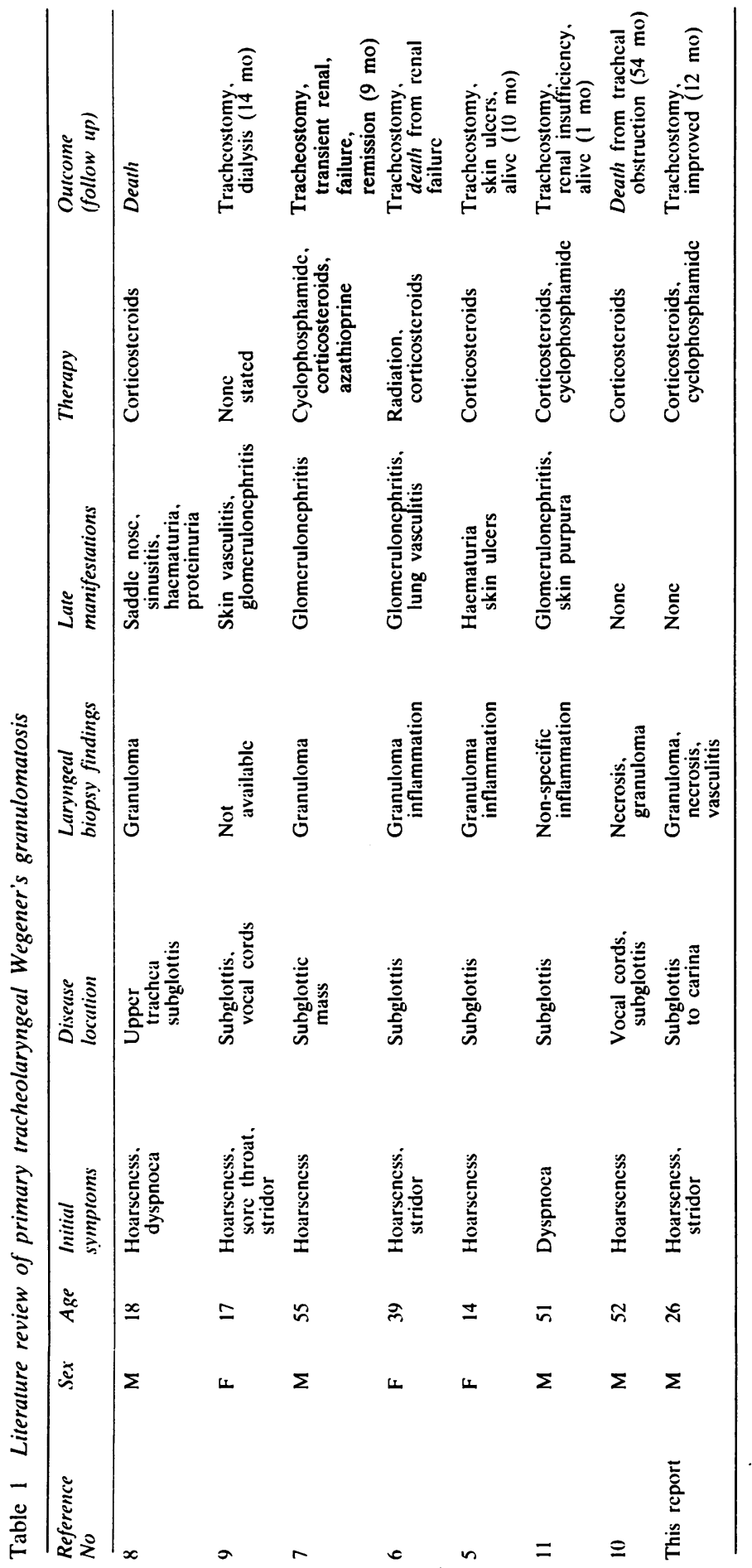


(CT) scan of the trachea showed concentric soft tissue, narrowing from the subglottic region to the left mainstem bronchus. A description of the CT findings has been reported previously. ${ }^{12}$

Because of the severity of the laryngeal obstruction a tracheostomy was performed and biopsy specimens were obtained. Cultures of the biopsy specimens were negative. One biopsy specimen from the anterior tracheal wall contained a zone of granulation tissue infiltrated by inflammatory cells. A small vessel located in a non-inflamed area showed a destructive granulomatous vasculitis (Fig. 1).

The diagnosis of Wegener's granulomatosis was made, and treatment was started with prednisone 60 $\mathrm{mg} /$ day and cyclophosphamide $150 \mathrm{mg} /$ day.

The stridor improved gradually. A CT scan in October 1985 showed a marked decrease in the soft tissue swelling throughout the larynx. When reevaluated in May 1986, the patient was asymptomatic. Indirect laryngoscopy confirmed improvement in glottic and subglottic airway size.

\section{Discussion}

Our patient's presentation was unusual in two regards: firstly, his Wegener's granulomatosis appeared to be limited to one region. and secondly. the region of involvement was the larynx and trachea. Wegener's granulomatosis typically presents as a multisystem illness. ${ }^{1-3}$ In some patients, however, the disease may appear to be limited to a single organ or region, most commonly the lung. ${ }^{2+}$ Many of these patients have subclinical evidence of other organ involvement or subsequently develop a life-threatening multisystem illness, thus emphasising the rarity of truly 'limited' disease. ${ }^{2}$

Wegener's granulomatosis presenting with isolated involvement of the trachea is rare. ${ }^{13}$ Only seven previous cases of documented isolated laryngeal Wegener's granulomatosis have been described. Laryngeal disease more commonly occurs as a late complication of fully developed or previously treated Wegener's granulomatosis. ${ }^{2}$ 5-11 1,3-27

Our patient's clinical picture resembles that of other patients with isolated laryngeal Wegener's granulomatosis (Table 1). ${ }^{5-11}$ That our patient is male is consistent with the slight male predominance found both in isolated laryngeal Wegener's granulomatosis $($ male/female $=2.3$ ) and in generalised Wegener's granulomatosis (male/female $=1 \cdot 6)$. His relatively young age ( 26 years) is not surprising since patients with isolated laryngeal Wegener's are on average younger ( 36 years) than patients with typical Wegener's granulomatosis (44 years). ${ }^{2}$
Indeed, three of the seven previously reporte patients with laryngeal Wegener's granulomatosi were adolescents. ${ }^{54}$ As with our patient. mos other patients presented with subacute stridor og hoarseness, or both.

Additional similarities between our patient an those listed in Table 1 became evident when th\& larynx and upper airways were evaluated. In mos patients, as in our case, direct laryngoscopy showed. involvement of the subglottic region. Vocal cord involvement was less common. The disease can bद्छ localised, often to the posterior wall of the subglottie region, or diffuse, with circumferential narrowing The mucosa may be erythematous, boggy. O\& ulcerated. Proliferation of granulation tissu迎 produces mass lesions in some patients. Extensiob of the disease below the carina is quite rare Tracheostomy was often required, as in ous patient, to ensure adequate ventilation during the acute inflammatory phase of the disease.

The recognition of isolated laryngeal Wegeneres granulomatosis is made especially difficult by the fact that the histopathology is often not considered diagnostic. $^{2 x}$ Typically, biopsy specimens from the upper respiratory tract of patients with Wegener granulomatosis show acute and chronic inflammio tion with necrosis. Granuloma are often present. bu vasculitis is rarely found. ${ }^{25}$ Multiple larynge $\bar{\Phi}$ biopsies were performed in most of the seves previous cases, and vasculitis was found in none. I\$ our patient. multiple biopsies at two different time $\overrightarrow{\overrightarrow{0}}$ were performed, one of which showed vasculitis making this only the second time that vasculitis hat been described on laryngeal tissue biopsy. ${ }^{25}$

The tendency to dismiss the diagnosis (थ Wegener's granulomatosis until and unless vasculit is demonstrated is incorrect and results from misconception of the clinicopathological featureis of Wegener's granulomatosis. 2x 5o Although Wegener's granulomatosis is usually classified as form of vasculitis. Wegener himself emphasised the importance of the necrosis with granuloma form tion. ${ }^{29}$ Of all the organs, the lung is the site wher both the vasculitis and the granulomatosis necrosis are most frequently seen.-2 Biopsy specimens from other sites, especially the upper respiratory tracio rarely show all the "classic' pathological finct
ings.

Thus the diagnosis of laryngeal Wegener granulomatosis depends on the presence of $\mathbb{D}_{0}$ consistent clinicopathological picture as well as the exclusion of the other causes of laryngeal ot struction, which have recently been reviewed i detail. 25 . 31

The outcome of primary laryngeal Wegener $\stackrel{\mathbb{D}}{\stackrel{\mathbb{R}}{8}}$ granulomatosis appears to depend on the timing ang 
the type of treatment. ${ }^{5-11}$ None of the seven previous cases received immunosuppressive therapy while the Wegener's granulomatosis was limited to the larynx. Subsequently, all seven developed either progressive laryngeal obstruction or disseminated disease (Table 1). Three patients, including our patient, were eventually treated with cyclophosphamide, and all improved. No patient remitted without cyclophosphamide therapy. This experience strongly suggests, but does not prove, the need for cyclophosphamide therapy in primary laryngeal Wegener's granulomatosis. Given the very poor outcome experienced by most patients with isolated laryngeal Wegener's granulomatosis who are untreated or treated after dissemination of their disease, early treatment with cyclophosphamide appears to be warranted.

\section{References}

1 Fahey J L. Leonard E. Churg J. Godman G. Wegener's granulomatosis. Am J Med 1954: 17: 168-79.

2 Fauci A S. Haynes B F, Katz P. Wolff S M. Wegener's granulomatosis: prospective clinical and therapeutic experience with 85 patients for 21 years. Ann Intern Med 1983: 98: 76-85.

3 Godman G C, Churg J. Wegener's granulomatosis: pathology and review of the literature. AMA Arch Pathol 1954; 58: $533-53$.

4 Carrington C B. Liebow A A. Limited forms of angiitis and granulomatosis of Wegener's type. Am J Med 1966: 41: 497-527.

5 Thomas K. Laryngeal manifestations of Wegener's granuloma. $J$ Laryngol Otol 1970); 84: 101-6.

6 Talerman A. Wright D. Laryngeal obstruction due to Wegener`s granulomatosis. Arch Otolaryngol 1972: 96: 376-9.

7 Terent A, Wibell L. Lindholm C E. Wilbrand H. Laryngeal granuloma in the early stages of Wegener's granulomatosis. $J$ Otorhinolaryngol Relat Spec 1980: 42: 258-65.

8 Atkins J P. Eisman S H. Wegener's granulomatosis. Ann Otol Rhinol Laryngol 1959: 68: 524-47.

9 Bohlman M E. Ensor R E. Goldman S M. Primary Wegener's granulomatosis of the trachea: radiologic manifestations. South Med J 1984: 77: 1318-9.

10 Kurita S. Hirano M. Wegener's granuloma localized in the larynx. Report of a case. Auris Nasus Larynx 1983: 10 (suppl): S97-104.

11 Scully R E, Galdabini J J, McNeely B U. Weekly clinicopathological exercises: case 24-1979. N Engl J Med 1979; 300: 1378-85.
12 Stein M G, Gamsu G, Webb W R. Stulbarg M S. Diffuse tracheal stenosis in Wegener's granulomatosis-the role of computed tomography. J Comput Assist Tomogr 1986; 10: $868-70$.

13 Waxman J. Bose W J. Laryngeal manifestations of Wegener's granulomatosis: case reports and review of the literature. $J$ Rheumatol 1986; 13: 2408-11.

14 McDonald T J. DeRemee R A. Rochester M N. Wegener's granulomatosis. Laryngoscope 1983; 93: 220-31.

15 Arauz J C. Fonseca R. Wegener`s granulomatosis appearing initially in the trachea. Ann Otol Rhinol Laryngol 1982: 91: 593-4.

16 McDonald $T$ J. Neel H B. DeRemee $R$ A. Wegener's granulomatosis of the subglottis and the upper portion of the trachea. Ann Otol Rhinol Laryngol 1982: 91: 588-92.

17 Kernblut A D. Wolff S M. DeFries H O. Fauci A S. Wegener's granulomatosis. Otolaryngol Clin North Am 1982: 15: 673-83.

18 Lampman J. Subglottic stenosis in Wegener's granulomatosis. Chest 1981: 79: 230-2.

19 Cohen S R. King K K. Landing B H. Isaacs H. Wegener's granulomatosis causing laryngeal and tracheobronchial obstruction in an adolescent girl. Ann Otol Rhinol Laryngol [Suppl] 1978: 87 (5 part 2 suppl 52): 15-19.

20 Chizhikov V M. Wegener's granulomatosis with involvement of the posterior wall of the pharynx. Vestn Otorinolaringol 1975; 5: 87 .

21 Kulis J C. Nequin N D. Tracheo-esophageal fistula duc to Wegener`s granulomatosis. JAMA 1965: 191: 148-9.

22 Brown $\mathrm{H} \mathrm{A}$. Woolner L B. Findings referable to the upper part of the respiratory tract in Wegener's granulomatosis. Ann Otol Rhinol Laryngol 1960; 69: 810-29.

23 Stratton H J M. Price T M L. Skelton M O. Granuloma of the nose and periarteritis nodosa. $\mathrm{Br}$ Med J 1953: i: 127-30.

24 Walton E W. Giant-cell granuloma of the respiratory tract (Wegener's granulomatosis). Br Med J 1958: ii: 265-70.

25 Scully R E. Mark E J. McNely B U. Case records of the Massachusetts General Hospital: weekly clinicopathological exercises. N Engl J Med 1986; 315: 378-87.

26 Cohen M I. Gose R M. August C Z. Ossoff R H. Tracheal and bronchial stenosis associated with mediastinal adenopathy in Wegener's granulomatosis: CT findings. J Comput Assist Tomogr 1984: 8: 327-9.

27 DeRemee R A. McDonald T J. Weiland L H. Wegener's granulomatosis: observations on treatment with antimicrobial agents. Mayo Clin Proc 1985: 60: 27-32.

28 Shah I A. Holstege A. Riede U N. Bioptic diagnosis of Wegeners granulomatosis in the absence of vasculitis and granulomas. Pathol Res Pract 1984: 178: 407-12.

29 Scully R E, Mark E J, McNeely B U. Case records of the Massachusetts General Hospital: weekly clinicopathological exercises. N Engl J Med 1981; 17: 999-1008.

30 Scully R E. Mark E J. McNeely B U. Case records of the Massachusetts General Hospital: weekly clinicopathological exercises. $N$ Engl J Med 1985; 313: 1530-7. 